\title{
Laboratory-scale Experiment for an Active-stage Composting Process under the Same Material and Operating Conditions
}

\author{
Takenobu SHISHIDO a and Hirakazu SEKI ${ }^{\text {a, }}{ }^{\dagger}$ \\ (a Kanazawa University, Kanazawa, 920-1192 Japan)
}

\begin{abstract}
We conducted a laboratory-scale composting experiment with forced aeration using two fermenters with the same shape and geometry under the same material and operating conditions to certify the reproducibility and construct a mathematical model for the proposed composting process as an ecosystem phenomenon. Overall, the reproducibility of the composting process was relatively good, although small differences in the temperature and heat generation rate between the two fermenters occurred after $100 \mathrm{~h}$, and these differences gradually increased toward the end of the experiment. Based on these results, it seems feasible to simulate the composting process with a deterministic model to examine the behavior of the entire system for the purposes of basic system design. We propose a deterministic model for heat and mass transfer in the composting process, emphasizing that the transformation process of released biochemical energy to heat involves an "energy dissipation mechanism" as a successive substrate decomposition process. The simulated model results of the temperature, moisture content, weight, oxygen concentration, and heat generation rate were in fairly good agreement with the experimental results. However, the course of the heat generation rate over time, that is, the reaction rate at any height in the vertical direction, somewhat differed from those estimated by the measured temperature profile.
\end{abstract}

Key words: Biochemical reaction, Composting, Dissipative structure, Ecosystem, Mathematical modeling.

\section{Introduction}

The effective use of biomass is one of the important themes in agricultural engineering based on the interpretation and application of ecological phenomena with respect to plant behavior. Two good examples are the use of compost as an excellent soil amendment and the use of heat generated in the composting process. Several papers on composting process modeling have been published (Finger et al., 1976; Fujita, 1980; Seki and Komori, 1984; Bach et al., 1987, Nakasaki et al., 1987; Hamelers, 1993; Keener et al., 1993; Kaizer, 1996; Stombaugh and Nokes, 1996; Das and Keener, 1997; VanderGheynst et al., 1997; Seki, 2002). Since composting is a complicated phenomenon involving simultaneous heat and moisture transfer with microbial reactions in dispersed phases of solid, liquid, and gas, effective models directly related to the practical application of composting are yet to be proposed.

Recently proposed detailed simulation models (Sole-Mauri et al., 2007; Bongochugetsakul and Ishida, 2008; Hiraishi et al., 2012; Nakayama et al., 2007a; Nakayama et al., 2007b) show an increased recognition of the effectiveness of using unused biomass along with an upgrade in the numerical techniques being used. Although sensitivity analyses have been applied to these models, confirmation of their reproducibility has been insufficient, and further research is required to bring them up to the level required for effective practical use.

In this study, we interpret composting as an ecological phenomenon involving microorganisms and provide useful infor-

\footnotetext{
Received; May 27, 2014.

Accepted; February 21, 2015.

†Corresponding Author: seki@se.kanazawa-u.ac.jp

DOI: 10.2480/agrmet.D-14-00010
}

mation on effective composting operations. Specifically, we address the following subjects:

1) In a laboratory-scale composting experiment under nearly identical material and operating conditions, we confirm the reproducibility of the composting process and discuss the observed shift of microbes and substrates during composting.

2) Regarding composting as a dissipative structure (Nicolis and Prigogine, 1977) and assuming the mechanism characteristic of an energy dissipation structure, we construct a simulation model of an in-vessel composting process and certify its validity by comparing our theoretical results with the experimental ones.

\section{Theory and Mathematical Modeling}

\subsection{Biochemical reaction modeling}

We developed a mathematical model by which we can properly express the experimental results, and which are discussed below in section First, we assume the composting process to be an ecological phenomenon that develops a dissipative structure. A dissipative structure is a stable state that forms in an open system, which is far from being an equilibrium state (Nicolis and Prigogine, 1977). For dissipative structures, there are some rules for the redistribution of the exergy released and supplied to the system (e.g., Silow et al., 2011). For example, one rule states that the released exergy is used to maximize the amount of exergy accumulated in the constructed dissipative structure (Jorgensen, 2001). This rule has been suggested to connect to the rule of formation of the dissipative structure; however, a detailed model to quantitatively express this rule has not yet been developed.

Some mathematical model is therefore required to characterize the microbial reaction that corresponds to the formation of the dissipative structure, such as the Lotka-Volterra model or the logistic model based on the empirical aspect of the dissipative structure formation (Nicolis and Prigogine, 1977). However, it is 
not easy to define and determine the parameters for these models for their application to the composting process. Therefore, we propose a more tractable mathematical microbial reaction model using the following assumptions that are based on conventional chemical engineering techniques:

1) A composting reaction obeys the 1st order decomposition reaction of the four types of substrates.

2) One type of microbe decomposes only one type of target substrate.

3) Substrate succession obeys a "time lag plus 1st order delay" system.

As for assumption 1, the first order reaction, as based on the expression by Haug (1993) and Keener et al. (1993), holds in the case of a large Contois constant value in a Contois model that has been experimentally proven to be applicable to the composting process (Fujita, 1993). Four types of substrates are identified from the experimental temperature data, which have different degrees of biodegradability and temperature dependence. Assumption 2 indicates that there is no competition between the many types of microbes to obtain the same substrate; that is, each type of microbe decomposes only one type of target substrate. In assumption 3, the term lag time refers to the time interval required to reach the prescribed temperature, as determined by the temperature dependency of the microbes that decompose the target substrate, and the time constant is a reflection of the microbe's habituation. First, we determine the time required to reach the harmonic growth stage; that is, the logarithmic growth stage. In this case, the reaction rate coefficient $k_{i}$, in a period from the start of degradation of the prescribed substrate $i$ to the time it reaches the logarithmic growth stage, is governed by the following equation:

$$
\begin{array}{ll}
\frac{d k_{i}}{d t}=\alpha_{i}\left(k_{i 0}-k_{i}\right) & (i=1,2,3,4) \\
t=t_{i} ; & k_{i}=0,
\end{array}
$$

where $k_{i 0}$ is the reaction rate coefficient in the logarithmic growth stage, $\alpha_{i}$ is the reciprocal of the time constant, and $t_{i}$ is the delayed time lag until the composting reaction starts. Introduction of "time lag plus 1st order delay" to composting systems has been previously applied by Seki and Komori (1984) .

Based on the above assumptions, equations for the biochemical reaction rate are written as follows:

$$
\begin{array}{ll}
R_{s i}=-k_{i} S_{i} & (i=1,2,3,4), \\
R_{X i}=-Y R_{s i} & (i=1,2,3,4), \\
R_{w}=-Y_{W / S} \sum_{i=1}^{4} R_{s i}, & \\
R_{O}=Y_{O / S} \sum_{i=1}^{4} R_{s i}, & \\
R_{H}=\Delta h_{S} \sum_{i=1}^{4} R_{s i}, &
\end{array}
$$

where $R_{s i}$ is the rate of decomposition of substrate $i, R_{x i}$ is the rate of growth of the microorganism corresponding to the decomposition of the substrate $i, R_{w}$ is the rate of water formation from the growth reaction of the microorganisms, $R_{O}$ is the rate of oxygen consumption with substrate decomposition, $R_{H}$ is the rate of heat generation with substrate decomposition, $Y$ is the cell yield for the composting reaction, $Y_{w / s}$ is the mass of water produced by the decomposition of a unit mass of the substrate, $Y_{o / s}$ is the mass of oxygen consumed by the decomposition of a unit mass of the substrate, and $\Delta h_{s}$ is the enthalpy change for the substrate decomposition reaction.

The reaction rate coefficient $k_{i}$ is expressed as

$$
k_{i}=k_{i \max } f_{T i}(T) f_{w}(w) f_{O}(O)\left\{1-e^{-\alpha_{i}\left(t-t_{i}\right) u\left(t-t_{i}\right)}\right\},
$$

where $T$ is the temperature, $w$ is the moisture content, $O$ is the oxygen concentration, and $f_{T i}(T), f_{w}(w)$, and $f_{o}(O)$ are

$$
\begin{aligned}
& f_{T i}(T)=\frac{B+A}{B e^{-A\left(T-T_{i}^{*}\right)+} A e^{B\left(T-T_{i}^{*}\right)}} \quad(i=1,2,3,4), \\
& f_{w}(w)=\left(1-e^{-50 w^{4}}\right) e^{-100 w^{30}}, \\
& f_{O}(O)=\frac{O}{K_{O}+O} .
\end{aligned}
$$

Eq. (9) is a simplified expression of the temperature dependence of $k_{i}$ (Seki, 2014), based on the equation used by Seki and Komori (1992) and Seki (2002). Eq. (10) is a continuous form expression of the moisture dependence of $k_{i}$ from the discrete form of the equation shown in Seki (2002). The term $u\left(t-t_{i}\right)$ is Heaviside's step function [ $\left.=1\left(t>t_{i}\right), 0\left(t<t_{i}\right)\right], A$ and $B$ are positive parameters relating to reaction characteristics, $K_{O}$ is the saturation constant of oxygen, and $T_{i}^{*}$ is the optimal temperature for the microorganisms decomposing substrate $i$. Moreover, $f(O)$ is a mono-type expression proposed by Haug (1993). The values of these parameters are shown in Table 1.

\subsection{Transport phenomena model with a biochemical reaction}

Regarding mixed compost materials as a continuum, we constructed a macroscopic model (Bear and Bachmat, 1991) of the composting process. This model is based on Seki's model (2002), but it contains an upgrade and two simplifications. The upgrade is our introduction of 4 types of substrates having different degrees of biodegradability and temperature dependence. We simplified Seki's model by disregarding the change in the volume of the compost materials and the moisture diffusion during the composting process because of their insignificant contributions. Our assumptions are as follows:

1) Solid, liquid, and gas phases coexist in the representative elementary volume [REV, (Bear and Bachmat, 1991) ], and microbial reactions and phase changes (water evaporation and condensation) occur uniformly in the REV.

2) Air flows vertically downward (z-direction) from the top of the compost mass at a constant rate.

3) Vertical fluxes of the moisture and oxygen transfers in the gas phase are governed by convective transport because the diffusive fluxes are extremely small compared with the convective fluxes.

4) The quasi-steady-state approximation holds for humidity $H$, enthalpy $i$, and oxygen concentration $O$ in the gas phase.

5) Liquid water moves according to the extended Darcy's law (e.g., Hillel, 1971). 
Table 1. Values of parameters used for theoretical calculation.

\begin{tabular}{|c|c|c|}
\hline$Y$ & $\begin{array}{l}\text { mass of microbes produced by oxidation of the unit mass of substrate(growth yield } \\
\text { of microbes) }\end{array}$ & $0.35[-]$ \\
\hline$Y_{w / s}$ & mass of water produced by decomposition of the unit mass of substrate & $0.535[-]$ \\
\hline$Y_{o / s}$ & mass of oxygen consumed by decomposition of the unit mass of substrate & $1.35[-]$ \\
\hline$\Delta h_{s}$ & enthalpy change for substrate decomposition process & $18000\left[\mathrm{~kJ} \mathrm{~kg}^{-1}-\mathrm{DS}\right]$ \\
\hline$\alpha_{1}$ & reciprocal of time constant for decomposition of substrate 1 & $0.02\left[\mathrm{~h}^{-1}\right]$ \\
\hline$\alpha_{2}$ & reciprocal of time constant for decomposition of substrate 2 & $0.02\left[\mathrm{~h}^{-1}\right]$ \\
\hline$\alpha_{3}$ & reciprocal of time constant for decomposition of substrate 3 & $0.05\left[\mathrm{~h}^{-1}\right]$ \\
\hline$\alpha_{4}$ & reciprocal of time constant for decomposition of substrate 4 & $0.01\left[\mathrm{~h}^{-1}\right]$ \\
\hline$t_{1}$ & delayed time lag until starting of substrate 1 & $0[\mathrm{~h}]$ \\
\hline$t_{2}$ & delayed time lag until starting of substrate 2 & $0[\mathrm{~h}]$ \\
\hline$t_{3}$ & delayed time lag until starting of substrate 3 & $15[\mathrm{~h}]$ \\
\hline$t_{4}$ & delayed time lag until starting of substrate 4 & $6[\mathrm{~h}]$ \\
\hline$k_{1 \max }$ & reaction rate coefficient in the logarithmic growth state for substrate 1 & $0.8\left[\mathrm{~h}^{-1}\right]$ \\
\hline$k_{2 \max }$ & reaction rate coefficient in the logarithmic growth state for substrate 2 & $0.8\left[\mathrm{~h}^{-1}\right]$ \\
\hline$k_{3 \max }$ & reaction rate coefficient in the logarithmic growth state for substrate 3 & $0.15\left[\mathrm{~h}^{-1}\right]$ \\
\hline$k_{4 \max }$ & reaction rate coefficient in the logarithmic growth state for substrate 4 & $0.3\left[\mathrm{~h}^{-1}\right]$ \\
\hline$S_{10}$ & initial concentration of substrate 1 & $5\left[\mathrm{~kg} \mathrm{~m}^{-3}\right]$ \\
\hline$S_{20}$ & initial concentration of substrate 2 & $13\left[\mathrm{~kg} \mathrm{~m}^{-3}\right]$ \\
\hline$S_{30}$ & initial concentration of substrate 3 & $10\left[\mathrm{~kg} \mathrm{~m}^{-3}\right]$ \\
\hline$S_{40}$ & initial concentration of substrate 4 & $10\left[\mathrm{~kg} \mathrm{~m}^{-3}\right]$ \\
\hline$A$ & parameter in Eq.(9) & $0.13\left[\mathrm{~K}^{-1}\right]$ \\
\hline$B$ & parameter in Eq.(10) & $0.3\left[\mathrm{~K}^{-1}\right]$ \\
\hline$T_{1}^{*}$ & temperature at which degradation rate of substrate 1 shows maximum & $26\left[{ }^{\circ} \mathrm{C}\right]$ \\
\hline$T_{2}{ }^{*}$ & temperature at which degradation rate of substrate 2 shows maximum & $39\left[{ }^{\circ} \mathrm{C}\right]$ \\
\hline$T_{3}^{*}$ & temperature at which degradation rate of substrate 3 shows maximum & $56\left[{ }^{\circ} \mathrm{C}\right]$ \\
\hline$T_{4}{ }^{*}$ & temperature at which degradation rate of substrate 4 shows maximum & $58\left[{ }^{\circ} \mathrm{C}\right]$ \\
\hline$K_{O}$ & saturation constant for oxygen concentration & $0.057\left[\mathrm{~kg}-\mathrm{O}_{2} \mathrm{~m}^{-3}\right]$ \\
\hline$\rho_{a}$ & density of air & $1.1\left[\mathrm{~kg} \mathrm{~m}^{-3}\right]$ \\
\hline C & specific heat of the compost mass & $3.0\left[\mathrm{~kJ} \mathrm{~kg}^{-1} \mathrm{~K}^{-1}\right]$ \\
\hline$K$ & effective thermal conductivity of the compost mass & $0.9\left[\mathrm{~kJ} \mathrm{~m}^{-1} \mathrm{~h}^{-1} \mathrm{~K}^{-1}\right]$ \\
\hline$U$ & overall heat transfer coefficient at the side wall of the compost container & $1.68\left[\mathrm{~kJ} \mathrm{~m}^{-2} \mathrm{~h}^{-1} \mathrm{~K}^{-1}\right]$ \\
\hline$k_{s}$ & hydraulic conductivity & $0.00018\left[\mathrm{~m} \mathrm{~h}^{-1}\right]$ \\
\hline$m$ & exponent in Eq.(26) & $2[-]$ \\
\hline$w_{s t}$ & saturated moisture content & $0.8\left[\mathrm{~kg}-\mathrm{H}_{2} \mathrm{O} \mathrm{kg}^{-1}\right.$-total mass $]$ \\
\hline$C_{H}$ & humid heat of the humid air & $1.0\left[\mathrm{~kJ} \mathrm{~kg}^{-1} \mathrm{~K}^{-1}\right]$ \\
\hline$i_{0}$ & enthalpy of the air inlet & $34.4\left[\mathrm{~kJ} \mathrm{~kg}^{-1}-\mathrm{DA}\right]$ \\
\hline$H_{0}$ & humidity of the air inlet & $0.0088\left[\mathrm{~kg}-\mathrm{H}_{2} \mathrm{O} \mathrm{kg}^{-1}-\mathrm{DA}\right]$ \\
\hline$O_{0}$ & oxygen concentration of the air inlet & $0.232\left[\mathrm{~kg}^{-\mathrm{O}_{2}} \mathrm{~kg}^{-1}\right.$-air $]$ \\
\hline$T_{0}$ & temperature of the air inlet $(=$ atmospheric temperature $)$ & $20\left[{ }^{\circ} \mathrm{C}\right]$ \\
\hline$h_{\text {in }}$ & heat transfer coefficient at the top surface of the compost container & $10\left[\mathrm{~kJ} \mathrm{~m}^{-2} \mathrm{~h}^{-1} \mathrm{~K}^{-1}\right]$ \\
\hline$h_{o u}$ & heat transfer coefficient at the bottom surface of the compost container & $3\left[\mathrm{~kJ} \mathrm{~m} \mathrm{~m}^{-2} \mathrm{~h}^{-1} \mathrm{~K}^{-1}\right]$ \\
\hline
\end{tabular}

Under these assumptions, the balance equations for the substrate and microbes, moisture content, oxygen concentration, humidity, enthalpy, and heat are as follows:

$$
\begin{aligned}
& \frac{\partial S_{i}}{\partial t}=R_{s i} \quad(i=1,2,3,4), \\
& \frac{\partial X_{i}}{\partial t}=-Y \frac{\partial S_{i}}{\partial t} \quad(i=1,2,3,4), \\
& \frac{\partial(\rho \mathrm{w})}{\partial t}=-\rho_{l} \frac{\partial k}{\partial z}-k_{H} \alpha\left(H^{*}-H\right)+R_{w},
\end{aligned}
$$

$$
\begin{gathered}
\rho_{a} u \frac{\partial O}{\partial z}=R_{O} \\
\rho_{a} u \frac{\partial H}{\partial z}=k_{H} a\left(H^{*}-H\right) \\
\rho_{a} u \frac{\partial i}{\partial z}=k_{H} a\left(i^{*}-i\right) \\
C \rho \frac{\partial T}{\partial t}=\frac{\partial}{\partial z}\left(K \frac{\partial T}{\partial z}\right)-k_{H} a\left(i^{*}-i\right)+R_{H}-\frac{U l_{p}}{A_{b}}\left(T-T_{o}\right)
\end{gathered}
$$


The boundary and initial conditions are:

$$
\begin{gathered}
z=0 ; \frac{\partial(\rho w)}{\partial t}=-k_{H} a\left(H^{*}-H\right)+R_{w}, O=O_{0}, \\
H=H_{0}, i=i_{0}, K \frac{\partial T}{\partial z}=h_{i n}\left(T-T_{i a}\right) \\
z=l ; \quad-K \frac{\partial T}{\partial z}=h_{o u}\left(T-T_{e a}\right),
\end{gathered}
$$

$t=0 ; S_{i}=S_{i 0}, X_{i}=X_{i 0}, w=w_{0}, T=T_{0} \quad(i=1,2,3,4)$,

In the above equations, $k$ is the hydraulic conductivity, $k_{H} a$ is the volumetric water vapor transfer coefficient, $H^{*}$ is the saturated humidity, $u$ is the airflow rate averaged over the cross sectional area of the compost bed, $i^{*}$ is the saturated enthalpy of humid air, $C$ is the specific heat of the mixed compost materials, $\rho$ is the density of the entire volume of the compost material, $K$ is the thermal conductivity of the compost materials, $U$ is the overall heat transfer coefficient at the side wall of the compost container, $l_{p}$ is the perimeter of the compost container, $A_{b}$ is the base area of the packed compost materials, $T_{0}$ is the standard temperature (atmospheric temperature) that is assumed to be equal to the initial temperature in the mixed compost materials, $h_{i n}$ is the heat transfer coefficient at the top surface of the packed compost materials, $T_{i a}$ is the temperature in the air chamber above the mixed compost materials, $h_{o u}$ is the heat transfer coefficient at the bottom of the packed compost materials, $T_{e a}$ is the temperature in the air chamber just below the mixed compost materials, $S_{i 0}$ is the initial mass of substrate $i$ per unit volume, $X_{i 0}$ is the initial mass of microbe $i$ per unit volume, and $w_{0}$ is the initial moisture content of the mixed compost materials.

In Eq. (18), the second term on the right-hand side is the enthalpy loss with water evaporation and the third term is the actual heat generation rate with biodegradation.

As $R_{s i}, R_{w}, R_{o}$, and $R_{H}$ are nonlinear equations, it is difficult to obtain analytical solutions for $S_{i}, X_{i}, w, O, H, i$, and $T$. However, numerical solutions can be obtained by applying the finite differ- ence method.

\section{Experiment}

Experiments were conducted using fermenters with the same size and shape as those used in the experiments described by Seki and Shijuku (2012). Each fermenter (sample container) is a $0.022 \mathrm{~m}^{3}$ cylindrical vessel composed of a 10 -mm-thick acrylic resin, with an inner diameter of $200 \mathrm{~mm}$ and a height of $690 \mathrm{~mm}$. Air chambers were set at the top and bottom of the fermenters. Ten pairs of $\mathrm{Cu}-\mathrm{Co}$ thermocouples were set along the vertical center line of each fermenter, with two pairs in the two air chambers and one pair in the surrounding air for temperature measurement.

After packing the compost materials, air was directed continuously from the top of the container to maintain aerobic conditions in the inner compost material. The aeration gas exhausted from the container has a high $\mathrm{CO}_{2}$ concentration and high humidity; therefore, we measured the oxygen concentration after dehumidifying the humid air with a dehumidifier. Further details of the apparatus are provided in Seki and Shijuku (2012).

Using the identical fermenters, we conducted the compost experiment with the same airflow rate and compost material content in each. We continuously measured the temperatures, outlet oxygen concentrations, and the amounts of leachate water from the fermenters. The fermenters were each placed on balancers, and we measured changes in their weight at set time intervals. At the completion of the experiment, we measured the moisture content at specific heights and the $\mathrm{C}$ and $\mathrm{N}$ contents of compost samples.

Table 2 shows basic data on the organic materials used in the experiment and the experimental operating conditions.

\section{Results and discussion}

\subsection{Experimental results and repeatability of the composting} process

(1) Temperature and moisture content

Table 2. Organic materials used for experiment and operating conditions.

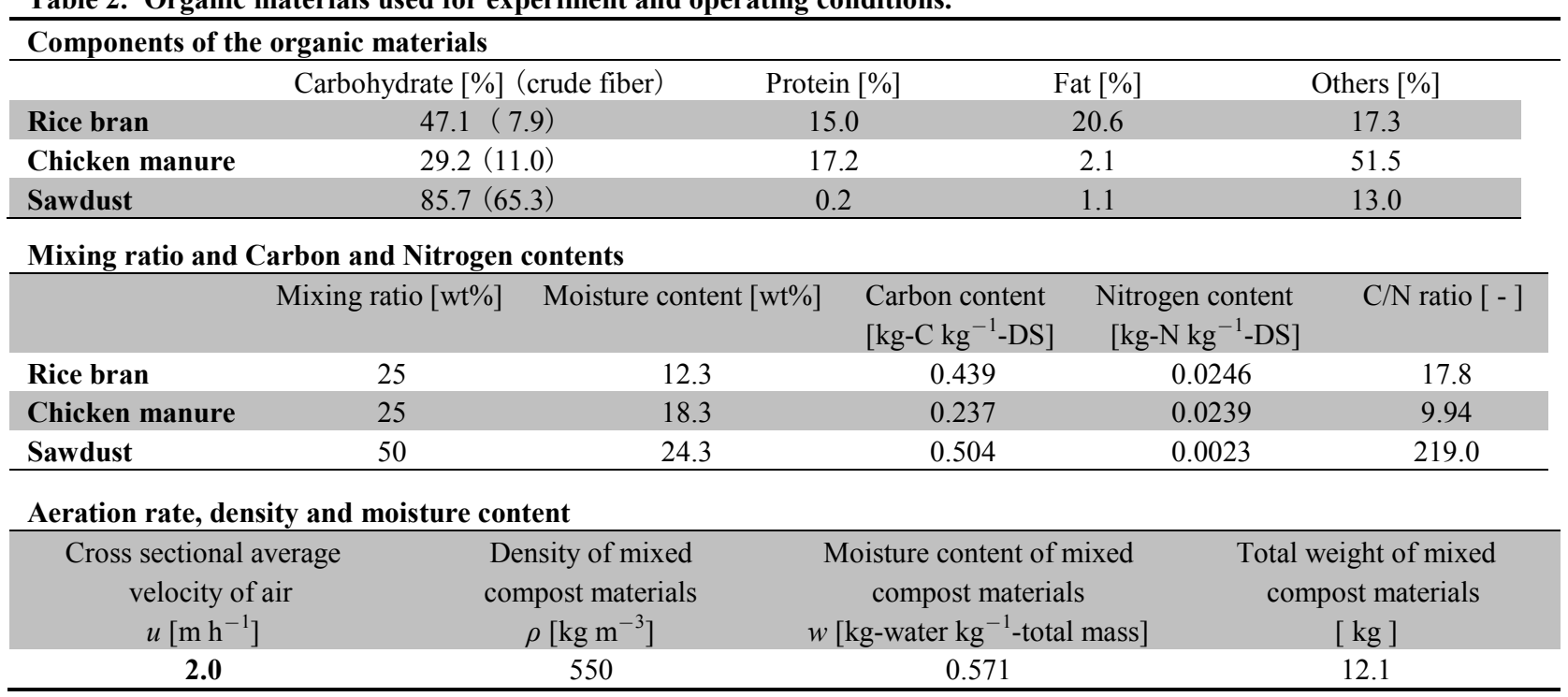


Figs. 1a and $\mathrm{b}$ show the temperature history at vertical positions $z=0.03,0.10,0.24,0.38,0.52$, and $0.66 \mathrm{~m}$, where $z$ is the distance from the top of the fermenter. As shown in the figures, the temperature history for the fermenters is almost identical. Temperature increased downward from near the top position due to the influence of the convective heat flow with aeration. In the bottom region, where $z=0.66 \mathrm{~m}$, the temperature drop at a later stage was significant when compared with the central region where $z=0.24$, 0.38 , and $0.52 \mathrm{~m}$. This is because water generated by the composting reaction moves downward, thereby increasing the bottom
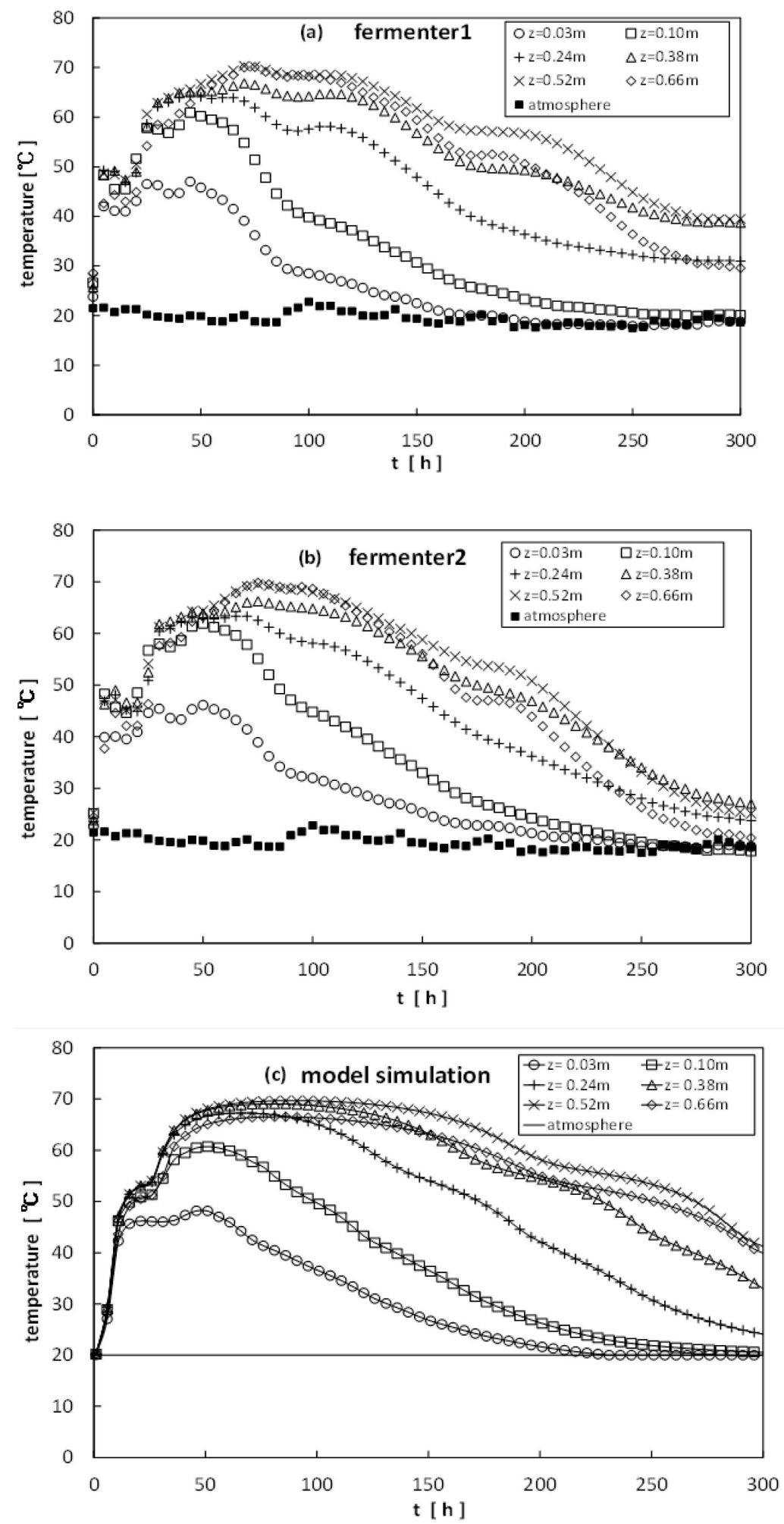

Fig. 1. Temperature history at vertical positions $z=0.03,0.10,0.24,0.38,0.52$, and $0.66 \mathrm{~m}$.

[ (a) fermenter 1, (b) fermenter 2, (c) model simulation ] 


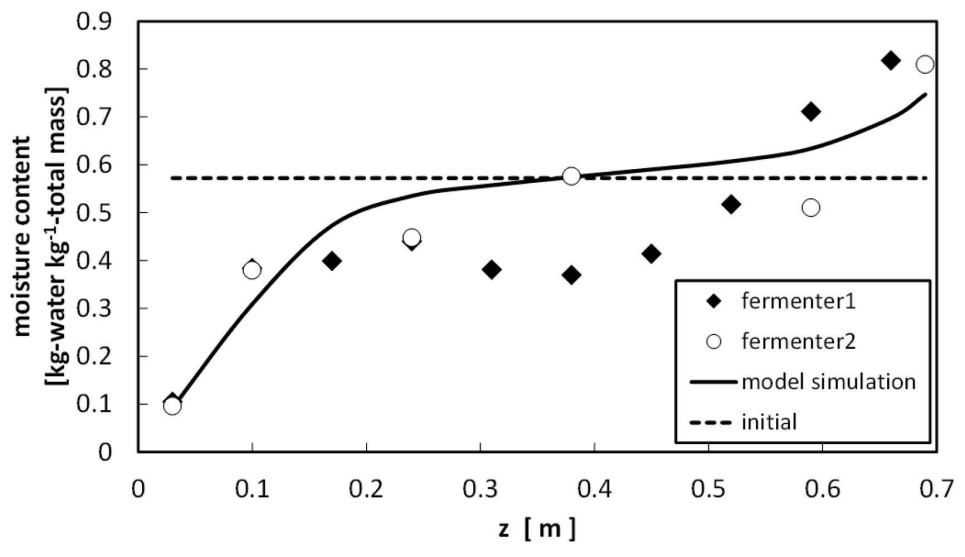

Fig. 2. Initial and final moisture profiles along the vertical direction.

moisture content. As a result, the heat capacity increases and the temperature rise typically associated with heat generation is suppressed. Temperature in both fermenters increased to approximately $50^{\circ} \mathrm{C}$ by $t=20 \mathrm{~h}$, and then gradually decreased. However, the temperature increased and attained a maximum value of approximately $70^{\circ} \mathrm{C}$ at $t=70 \mathrm{~h}$.
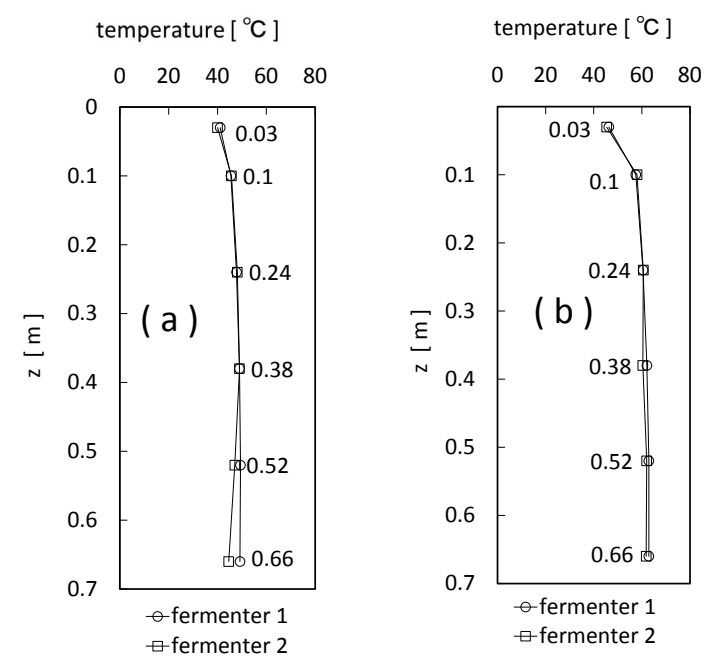

temperature $\left[{ }^{\circ} \mathrm{C}\right.$ ]

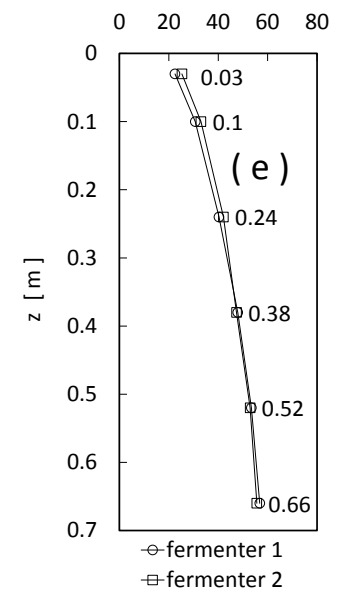

temperature $\left[{ }^{\circ} \mathrm{C}\right.$ ]

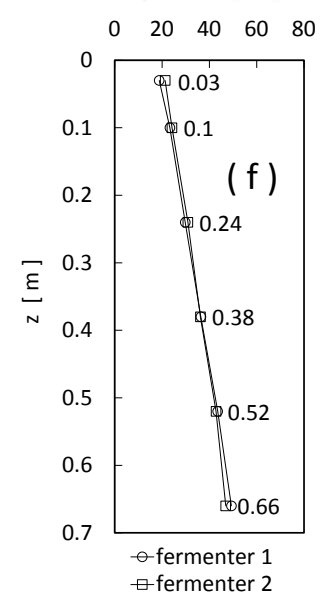

Figure 2 shows the initial and final moisture profiles along the vertical direction. We can see that the moisture content profiles are almost identical as well, although some difference is observed in the central region at $z=0.38 \mathrm{~m}$.

Figure 3 shows the temperature profiles in the fermenters at $t=$ $10,30,50,100,150,200,250$, and $300 \mathrm{~h}$. Results for both fer-
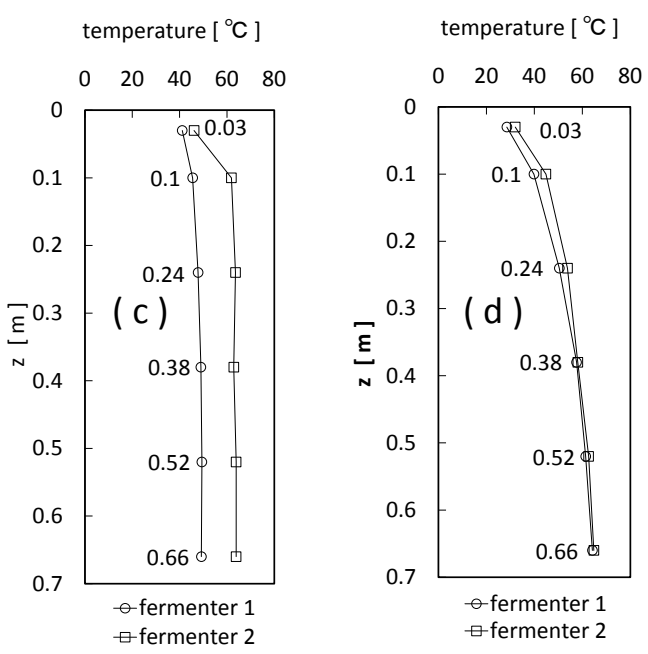

temperature $\left[{ }^{\circ} \mathrm{C}\right.$ ]

$\begin{array}{lllll}0 & 20 & 40 & 60 & 80\end{array}$

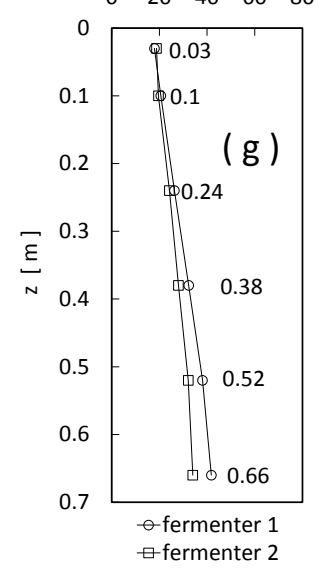

temperature $\left[{ }^{\circ} \mathrm{C}\right.$ ]

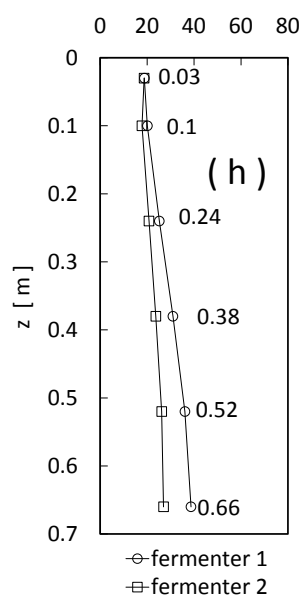

Fig. 3. Temperature profile in the fermenter at times $t=10,30,50,100,150,200,250$, and 300h.

[ (a) $t=10 \mathrm{~h},(\mathrm{~b}) t=30 \mathrm{~h}$, (c) $t=50 \mathrm{~h},(\mathrm{~d}) t=100 \mathrm{~h},(\mathrm{e}) t=150 \mathrm{~h},(\mathrm{f}) t=200 \mathrm{~h},(\mathrm{~g}) t=250 \mathrm{~h},(\mathrm{~h}) t=300 \mathrm{~h}$ ] 
menters were very similar at $t=10$ and $30 \mathrm{~h}$; however, there were differences at $t=50 \mathrm{~h}$. After $t=100 \mathrm{~h}$, the temperature gradually decreased and the fermenters once again show similar results. After $t=200 \mathrm{~h}$, we again observed differences in their temperature profiles near the bottom of the cylinders.

\section{(2) Oxygen concentration}

Figure 4 shows the oxygen concentrations at the fermenter outlets with time. Results for the fermenters were again very similar. From $t=4-9 \mathrm{~h}$, the oxygen concentration was below $10 \%$ and the minimum measured value was $0 \%$. These concentrations gradually recovered to reach values of approximately $18 \%$ at $t=13-15 \mathrm{~h}$, and then, decreased again to values below $10 \%$ at $t=24.5-32 \mathrm{~h}$, with a minimum measured value of approximately 5\%. Afterwards, however, they recovered to $12-13 \%$ and gradually decreased again until $t=70 \mathrm{~h}$, after which the oxygen concentrations slowly increased.

\section{(3) Changes in the weight of the fermenters}

Figure 5 shows the changes in the weight of the fermenters with time, which gradually decreased exponentially. The tendency of weight change for the two fermenters was almost identical.

Figure 6 shows the experimental results of the spatial average temperatures with time, and Figure 7 plots the changes of the temperature's spatial standard deviation with time. According to Fig. 6, the average temperatures in the fermenters coincide well up to $t=200 \mathrm{~h}$, but gradually differ afterwards. Furthermore, their standard deviations coincide until $t=100 \mathrm{~h}$, but differences between the two fermenters gradually increased after $t=100 \mathrm{~h}$.

The above results reveal that the two composting processes, operating under the same operating and material conditions, proceed in almost the same manner; hence, it seems appropriate and feasible to deterministically model the composting process using appropriate parameters. However, differences in the standard deviation between the two fermenters will not completely disappear

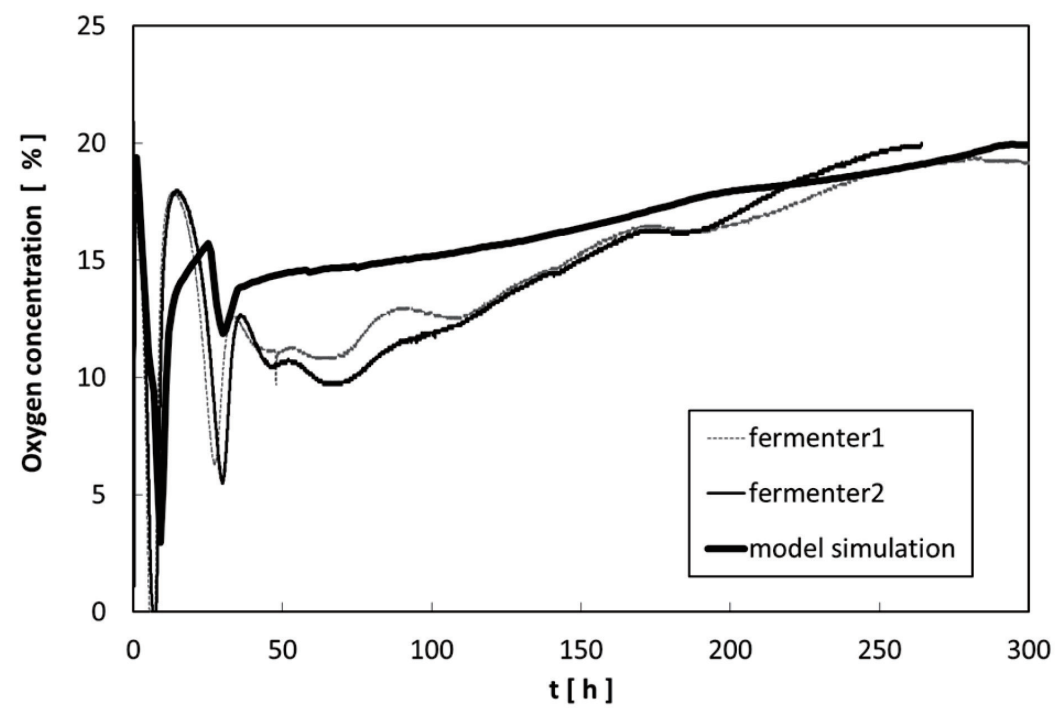

Fig. 4. Oxygen concentration at the exit of the fermenter with time.

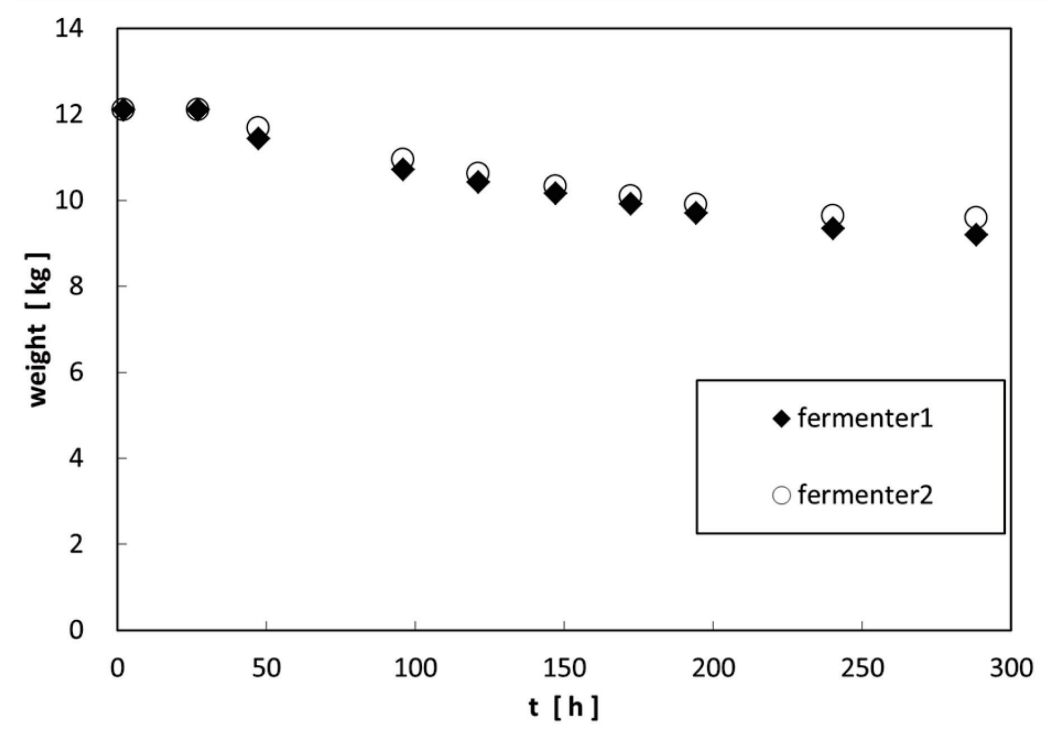

Fig. 5. Change in weight of the fermenters with time. 


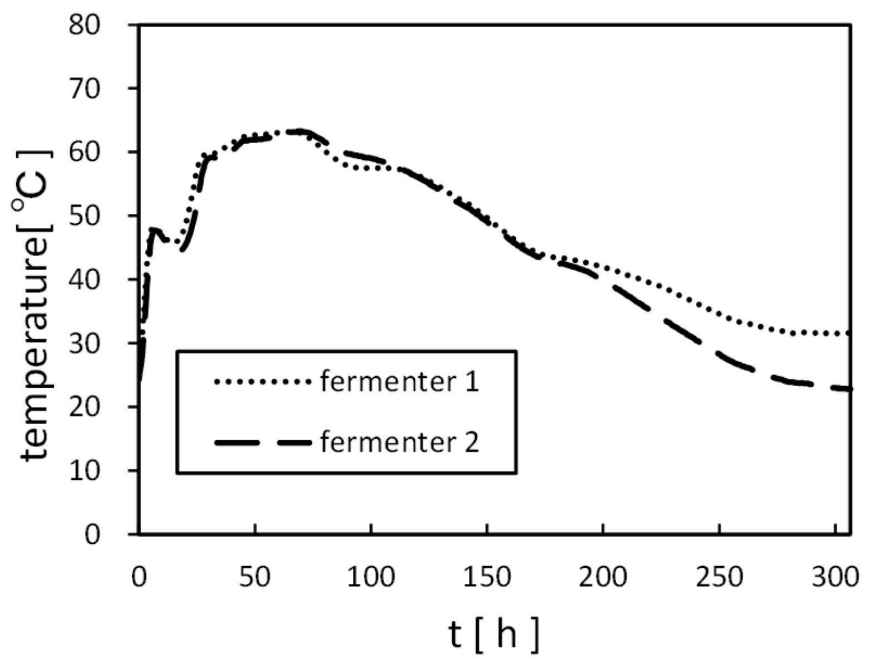

Fig. 6. Experimental results of the spatial average temperature with time.

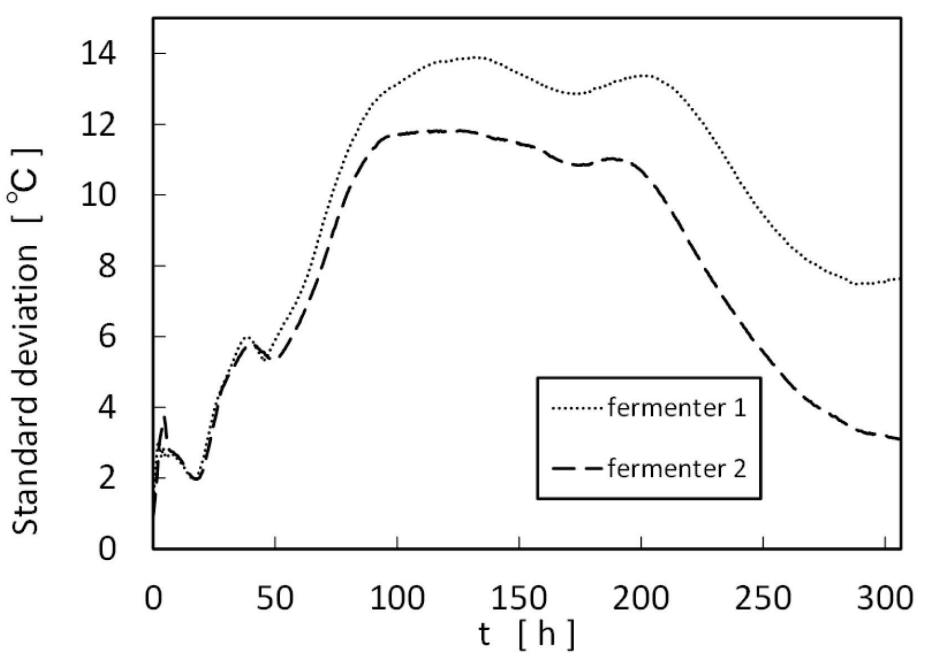

Fig. 7. Change in the spatial standard deviation of temperature with time.

even if we match their operating and material conditions. The reason for this is that it is very difficult to create and maintain completely uniform conditions in every detail by mixing compost materials, and unavoidable differences in the state variables will stem in the two fermenters. In response, we should consider gradually increasing the standard deviation with time. Since composting behavior is difficult to treat deterministically, we should also consider using the stochastic modeling proposed by Seki (2000).

\subsection{Shift of substrates for decomposition}

Following the procedure proposed by Seki and Shijuku (2012), we obtained the actual heat generation rate for the two fermenters. Figure 8 shows the relationship between the actual heat generation rate and temperature at $z=0.52 \mathrm{~m}$. From this figure, we can observe three phases. In the first phase $(t=0-8 \mathrm{~h})$, the heat generation rate maximizes at $36.7^{\circ} \mathrm{C}$ for both fermenters 1 and 2 , and the maximum heat generation rate was $11533 \mathrm{~kJ} \mathrm{~m}^{-3} \mathrm{~h}^{-1}$ for fermenter 1 and $11437 \mathrm{~kJ} \mathrm{~m}^{-3} \mathrm{~h}^{-1}$ for fermenter 2 . In the second phase $(t=8-28.5 \mathrm{~h})$, the heat generation rate maximizes at $56.6^{\circ} \mathrm{C}$ for fermenter 1 and $56.9^{\circ} \mathrm{C}$ for fermenter 2 , and the maximum heat generation rate was $6766 \mathrm{~kJ} \mathrm{~m}^{-3} \mathrm{~h}^{-1}$ for fermenter 1 and 7304 $\mathrm{kJ} \mathrm{m}^{-3} \mathrm{~h}^{-1}$ for fermenter 2 . We attribute the differences in the heat generation rates to the differences in the reaction mechanisms. In this case, mesophilic microbes are active in the first phase (2 kinds of flora, $i=1,2)$ and thermophilic microbes $(i=3)$ are active in the second phase. The third phase $(t>28.5 \mathrm{~h})$ is also thermophilic $(i=4)$, but there was no clear temperature showing the maximum heat generation rate.

Figure 9 shows the changes in the temperature and heat generation rate at $z=0.52 \mathrm{~m}$, and the oxygen concentration rate at the air chamber outlet with time. Since composting proceeds aerobically, if the oxygen supply rate is greater than the microbial oxygen consumption rate, the internal oxygen concentration in the container increases, and vice versa. The heat generation rate in the third phase is very small compared with the first and second phases; hence, the reaction in the third phase would be different from the reaction in the first and second phases. That is, the types of microbe and substrate in the third phase would be different from those in the first and second phases. From the above results and 

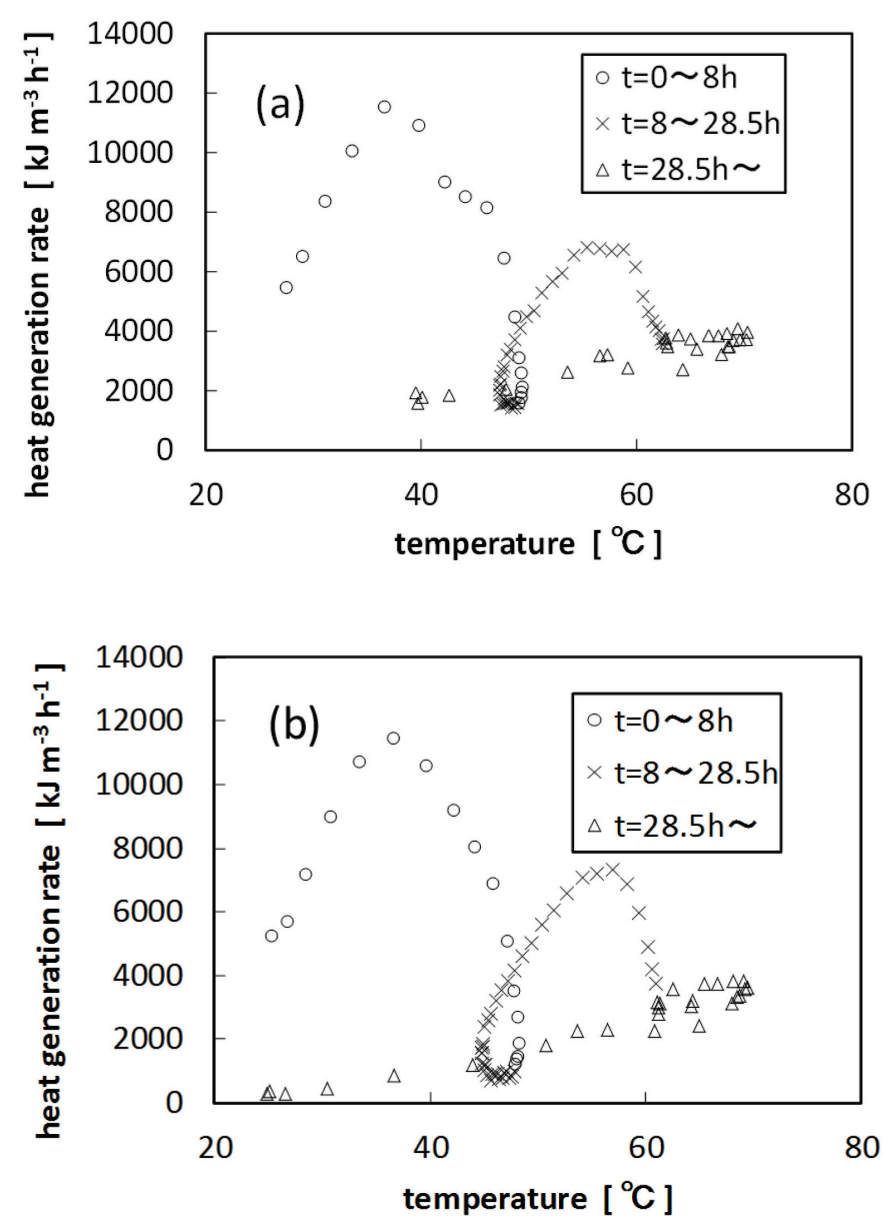

Fig. 8. Relationship between the actual heat generation rate and temperature for the two fermenters.

[ (a) fermenter 1, (b) fermenter 2 ]

those in the literature (Paul and Geesing, 2009), we surmised that there were four kinds of substrates that corresponded to the observed first, second, and third phases. However, we have not yet directly examined these substrates. Substrate types would include a polysaccharides group and a fat group for the first phase, a protein group for the second phase, and cellulose and hemi-cellulose groups for the third phase. Possible corresponding microbial groups might be bacteria for the first and second phases, and fungi or actinomycetes for the third phase.

\subsection{Comparison of model simulation and experimental results}

\section{(1) Several coefficients and parameters}

In numerical calculations, the equations for $H$ and $i$, that is, Eqs. (16) and (17), are discretized at every small increment of distance $\Delta z$, and the following analytical solutions are employed for the calculations:

$H_{j}=\left\{\begin{array}{l}H_{0} \\ H^{*}\left(T_{j}\right)-\left\{H^{*}\left(T_{j}\right)-H_{j-1}\right\} e^{-\frac{k_{H} a}{\rho_{a} u} \Delta z}(j=2 \cdots J)\end{array}\right.$,

$i_{j}=\left\{\begin{array}{lc}i_{0}+C_{p a}\left(T_{1}-T_{0}\right) & (j=1) \\ i^{*}\left(T_{j}\right)-\left\{i^{*}\left(T_{j}\right)-i_{j-1}\right\} e^{-\frac{k_{H} a}{\rho_{a} u} \Delta z} & (j=2 \cdots J)\end{array}\right.$,

where $j$ is the number of the grid $(1-J)$, and $H^{*}(T)$ and $i^{*}(T)$ are the humidity and enthalpy for saturated air, respectively, which are approximated by the data tabulated by Uchida (1963) as follows:

$$
\begin{aligned}
& H^{*}(T)=0.0043 e^{0.0599 \mathrm{~T}}, \\
& i^{*}(T)=18.201 e^{0.0547 T},
\end{aligned}
$$

where $T$ is the temperature $\left({ }^{\circ} \mathrm{C}\right)$.

We determined the effective thermal conductivity $K$ and heat capacity of the compost material $C$ using the empirical equations of Seki et al. (2014) and Seki (1990), respectively. The unsaturated hydraulic conductivity $k$ is assumed to be an exponential function of $w$, as in Campbell's equation (Campbell, 1985):

$$
k=k_{s}\left(\frac{w}{w_{s t}}\right)^{m},
$$

where $w_{s t}$ is the saturated moisture content, and $m$ is a power determined by trial and error so as to coincide as much as possible with the calculated moisture content and measured profiles. The saturated hydraulic conductivity $k_{s}$ is determined by the following equation, deduced from the amount of measured leachate and the flow-out duration time, assuming that the water diffusion effect can be neglected and the water is saturated at the bottom of the fermenter, where the hydraulic gradient is 1 : 

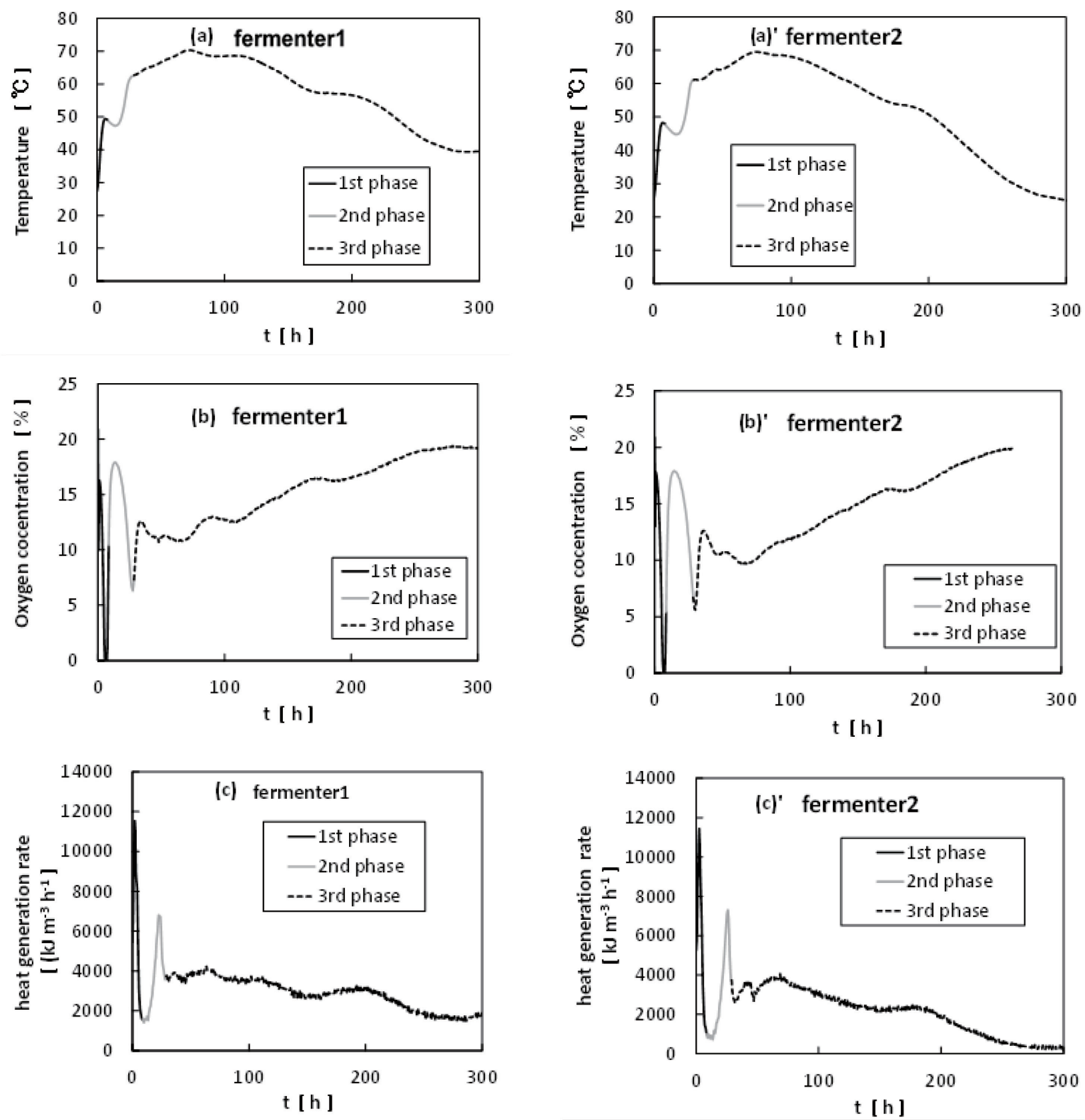

Fig. 9. Change in temperature at the position $z=0.52 \mathrm{~m}$, heat generation rate, and oxygen concentration of outlet air with time.

$$
k_{s}=\frac{\text { effuluent water quantity }}{(\text { crosss } \sec \text { tional area }) \times(\text { duration of flowout })} .
$$

We estimate the volumetric mass transfer coefficient $k_{H} a$ for the water vapor transfer due to aeration using the following equation proposed by Seki and Komori (1984):

$$
k_{H} a=\frac{55.2 \sqrt{\rho_{a} u}}{C_{H}} .
$$

We estimated the value of the overall heat transfer coefficient at the side wall of the compost container $U$ using the thermal conductivity and thickness of the polystyrene resin container wall.

\section{(2) Temperature distribution}

Figure 1c shows the calculation results for temperature history in the model simulation, which agree well with the experimental results in the following respects: 1$)$ the increase in the initial stage $(t=0-10 \mathrm{~h}), 2)$ the transition in biodecomposition from mesophilic to thermophilic microbes $(t=20-30 \mathrm{~h}), 3)$ a stable high temperature period $(t=30-70 \mathrm{~h})$, and 4) a slow temperature decrease $(t=100-200 \mathrm{~h})$. However, there was a difference between the theoretical and experimental results with respect to the temperature decrease after $t=200 \mathrm{~h}$, and a temporary drastic temperature drop $(t=10-20 \mathrm{~h})$. Specifically, in the early microbe shifting period at $t=10-20 \mathrm{~h}$, we observed a rapid temperature drop of approximately $5^{\circ} \mathrm{C}$ in the experiment, but the model simulation showed only temperature stagnation during this period. In fermenter 2 , the temperature dropped below $30^{\circ} \mathrm{C}$ at $t=300 \mathrm{~h}$, although the temperature held at $40^{\circ} \mathrm{C}$ near the bottom of the apparatus in fermenter 1 and in the model simulation. The temperature drop in fermenter 2 was because of the imbalance be- 
tween the oxygen supply by aeration and the oxygen consumption in the composting reaction due to the decrease in the apparent heat generation rate $R_{H}-k_{H} a\left(i^{*}-i\right)$.

\section{(3) Moisture content}

The calculation results of the final moisture profile are shown in Fig. 2. The simulation results show a moisture content of 0.55 $\mathrm{kg}$-water $\mathrm{kg}^{-1}$-total mass in the central position, $z=0.25-0.5 \mathrm{~m}$, which is larger than the experimental result $0.4 \mathrm{~kg}$-water $\mathrm{kg}^{-1}$-total mass. However, the calculated moisture content results agree well with the experimental results in the following three respects: 1) decreased moisture content near the entry of the aeration air (top of the fermenter), 2) homogeneity in the central region, and 3) increased moisture content near the exit of the aeration air (bottom of the fermenter). Figure 10 shows the calculated results of the changes in moisture content at each height in the fermenter with time. This figure shows a moisture content drop due to water evaporation near the entry of the aeration air and a moisture content increase due to vapor condensation near the exit of the aeration air.

\section{(4) Oxygen concentration at the outlet of the fermenter}

The calculated results of the oxygen concentration at the fermenter outlets are plotted in Fig. 4. These calculated results replicate the experimental results in the following respects: 1) an initial rapid decrease $(t=0-10 \mathrm{~h}), 2)$ a quick recovery $(t=10-20$ $\mathrm{h}), 3)$ a second decrease $(t=20-30 \mathrm{~h}), 4)$ a second recovery $(t=$ $30-40 \mathrm{~h})$, and 5) a slow recovery $(t=100-200 \mathrm{~h})$.

However, the drop in oxygen concentration during the $t=40$ $100 \mathrm{~h}$ period, and slight drop during $t=170-200 \mathrm{~h}$, are not reflected in theory. The former result is related to the disagreement between the experimental and theoretical temperatures in the central region, $z=0.24-0.52 \mathrm{~m}$. The latter is related to the shift in the theoretical temperature stagnation in the period $t=200-250 \mathrm{~h}$ (Fig. 1c). Although the reason for these results cannot be clarified here, we surmise that temporal and spatial changes in the substrate shift are not satisfactorily reflected theoretically.
The model simulation otherwise properly reflects the course of the reaction rate in the entire fermenter over time, as shown in this figure.

\section{(5) Heat generation rate}

Figure 11 shows a comparison of the calculated and experimental results of the heat generation rate at several heights in the fermenter. Initially, decomposition progressed from the top in the high temperature region, and later its reaction zone gradually shifted to a lower position for both calculated and experimental results. The calculated results, however, did not necessarily coincide with the experimental results at each height in the fermenter. For example, a substrate shift seems clear judging from a local temperature fluctuation in the theoretical results, but is not observed after $t=250 \mathrm{~h}$ in the experimental results. As indicated above, the substrate shift was not satisfactorily replicated theoretically. This is a point to be considered in the future.

In summary, the theoretical and experimental results are in fairly good agreement. Therefore, the proposed basic substrate shift reaction mechanism is a fairly good approximation that reflects the experimental results of the temperature profile and history, as well as the heat generation rate in the entire fermenter region. In the initial period, however, when there are drastic temporary and spatial changes in the heat generation rate, time, and position of the maximum value of the heat generation rate, there are differences between the theoretical and experimental results. Moreover, the accumulated discrepancy in the time of the substrate shifts results in some differences in the weight, moisture content, and temperature values between the theoretical and experimental results. In this respect, the introduction of a stochastic model will be available to consider the small differences in operation and material conditions. This issue remains as a future problem to address.

\section{Conclusions}

To clarify the reproducibility of the composting process and to construct a mathematical model of the process as an ecosystem

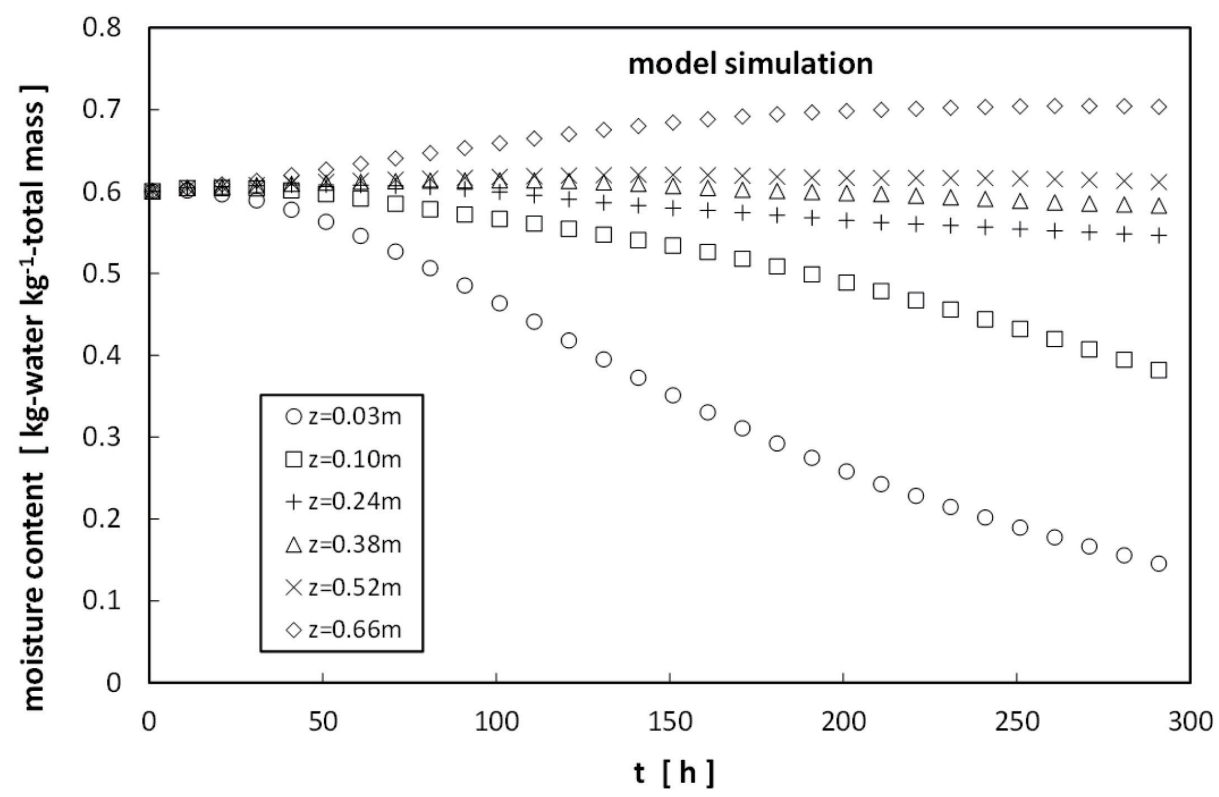

Fig. 10. Calculated results of the change in moisture content at each height in the fermenter with time. 

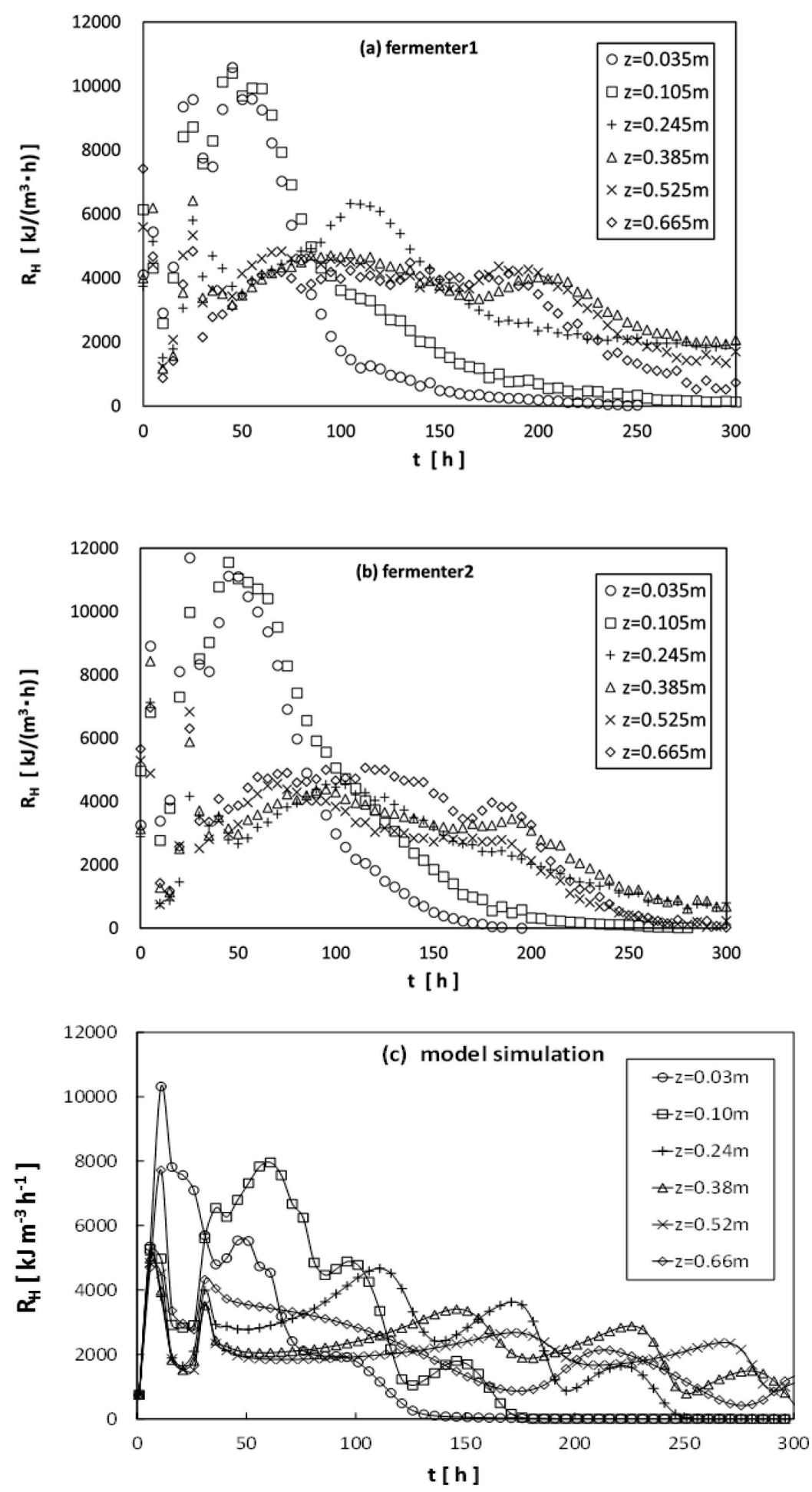

Fig. 11. Comparison of the calculated and experimental results of the heat generation rate at several heights in the fermenter.

phenomenon, we conducted a laboratory-scale composting experiment with forced aeration using two fermenters of the same shape and geometry under the same material and operating conditions.

According to the experimental results obtained from the two fermenters, the changes in temperature, heat generation rate, oxygen concentration at the exit of the aeration air, and weight with time coincide between the two fermenters until $100 \mathrm{~h}$ from the beginning of the experiment. However, a small difference be- tween the two fermenters accumulates with time after $100 \mathrm{~h}$, and this difference gradually increases toward the end of the experiment. As the reproducibility of the composting process is relatively good, simulating the process with a deterministic simulation model may be useful for examining the behavior of the entire system for the purposes of basic system design. For a total simulation including the uncertainty of reproducibility in the final stage, however, we suggest the application of stochastic modeling. 
We consider that the transformation process from the released biochemical energy to heat expresses the "energy dissipation mechanism" as a successive substrate decomposition process. Hence, we proposed a deterministic model of the heat and mass transfers with a biochemical reaction. The simulated results for temperature, moisture content, weight, oxygen concentration, and heat generation rate by the model were in fairly good agreement with the experimental results. However, the course of the heat generation rate over time, that is, the reaction rate at any given height in the vertical direction, somewhat differed from the rates estimated by the measured temperature profile.

\section{References}

Bach, P. D., Nakasaki, K., Shoda, M., and Kubota, H., 1987: Thermal balance in composting operations. Journal of Fermentation Technology, 65, 199-209.

Bear, J., and Bachmat,Y., 1991: Introduction to modeling of transport phenomena in porous media. Kluwer Academic Publishes, Dordrecht, Netherland, pp.553.

Bongochugetsakul, N., and Ishida, T., 2008: A new analytical approach to optimizing the design of large-scale composting systems. Bioresource Technology, 99, 1630-1641.

Campbell, G. S., 1985: Soil physics with BASIC, Elsevier, New York, pp. 150.

Das, K., Keener, H. M., 1997: Numerical model for the dynamic simulation of a large-scale composting system. Transactions of the ASAE, 40, 1179-1189.

Finger, S. M., Hatch, R. T., and Regan, T. M., 1976: Aerobic microbial growth in semisolid matrices: Heat and mass transfer limitation. Biotechnology and Bioengineering, 18, 1193-1218.

Fujita, K., 1980: Analysis of an aerobic composting digester with batch operation. In Management and Digestion of Solid Wastes, Kankyo Sangyo Shinbunsha, Tokyo, pp.462-475 (in Japanese).

Fujita, K., 1993: Composting technology. Gihodo shuppan, Tokyo, pp.196. (in Japanese).

Haug, R., 1993: The practical handbook of compost engineering. Boka Raton, Fla., Lewis publishers, pp.717.

Hamelers, H. V. M., 1993: A theoretical model of composting kinetics. In Science and engineering of composting: design, environment, microbial and utilization aspects (ed. by H. A. J. Hotink and H. M. Keener). Ohio State University, Columbus, pp.36-58.

Hillel, D., 1971: Soil and water - physical principles and processes. Academic Press, London, pp.288.

Hiraishi, T., Sagara, K., Yamanaka, T., Koutani, H., and Momoi, Y., 2012: Composting process model considering both ventilation by changing gas composition and moisture transfer by water potential. Journal of Environmental Engineering (Transactions of AIJ) , 77, 213-221 (in Japanese with English abstract).

Kaiser, J., 1996: Modeling composting as a microbial ecosystem: a simulation approach. Ecological Modeling, 91, 25-37.

Keener, H. M., Marugg, C., Hansen, R. C., and Hoitink, H. M., 1993: Optimizing the efficiency of the composting process In Science and engineering of composting: design, environment, microbial and utilization aspects (ed. by Hotink, H. A. J., and H. Keener, M.) . Ohio State University, Columbus, pp.59-94.

Jorgensen, S. E., 2001: Thermodynamics and ecological modeling, Lewis publishers, Boca Raton, pp.373.

Nakasaki, K., Kato, J., Akiyama, T., and Kubota, H., 1987: A new composting model and assessment of optimum operation for ef- fective drying of compost material. Journal of Fermentation Technology, 65, 441-447.

Nakayama, A., Nakasaki, K., Kuwahara, T., and Sano, Y., 2007a: A lumped parameter heat transfer analysis for composting processes with aeration. Transactions of the ASME, 129, 902-906.

Nakayama, A., Kuwahara, T., Sano, Y., Nakasaki, K., and Fujiwara, T., 2007b: A numerical modeling of composting process with aeration, Proceedings of the 2nd International Conference on Porous media and its Application in Science and Engineering. June 17-21, Kauai, Hawaii, pp.1-9.

Nicolis, G., and Prigogine, I., 1977: Self-organization in nonequilibrium systems. John Wiley \& Sons, New York, pp.491.

Paul, J., and Geesing, D., 2009: Composting facility operator manual. Abbotsford Printing Inc., British Columbia, pp.160.

Seki, H., 1990: Application of heat generated in compost to controlled environment agriculture. Ph.D. thesis presented to University of Tokyo, pp.216. (in Japanese).

Seki, H., 2000: Stochastic modeling of composting processes with batch operation by the Fokker-Planck equation. Transactions of the ASAE, 43, 169-179.

Seki, H., 2002: A new deterministic model for forced-aeration composting processes with batch operation. Transactions of the ASAE, 45, 1239-1250.

Seki, H., 2014: Development of a practical system of extraction and use of the heat generated in bamboo chip composting. Research report on a Grant-in-Aid for Scientific Research (B), No.2330149 from the Ministry of Education, Culture, Sports, Science and Technology, pp.196. (in Japanese)

Seki, H., and Komori, T., 1984: Composting reaction rate and simultaneous heat and mass transfer under the condition of forced aeration (in Japanese). Proceedings of JSCE, 351, 213-222.

Seki, H., and Komori, T., 1992: Structure of energy conversion in composting process. Journal of Agricultural Meteorology, 48, 225-235 (in Japanese with English summary).

Seki, H., and Shijuku, T., 2012: Estimating the heat generation rate in a forced-aeration composting process by measuring temperature changes. Journal of Agricultural Meteorology, 68, 107-120.

Seki, H., Oshima, K., Kiyose, S., and Sakida, S., 2014: Measurement of thermal conductivity of bamboo-chip pile, Proceedings of Annual Meeting of Hokuriku Chapter of the Society of Agricultural Meteorology of Japan, 39, pp.4-7 (in Japanese).

Silow, E. A., Mokry, A. V., and Jorgensen, S. E., 2011: Ecoexergy use for ecosystem health assessment, International Journey of Exergy. June 17, Paris, pp.1-22.

Sole-Mauri, F., Illa, J., Magri, A., Prenafeta-Boldu, F. X., and Flotats, X., 2007: An integrated biochemical and physical model for the composting process. Bioresource Technology, 98, 3278-3293.

Stombaugh, D. P., and Nokes, S. E., 1996: Development of a biologically based aerobic composting simulation model, Transactions of the ASAE, 39, 239-250.

Uchida, H., 1963: Shimeri Kuuki to Reikyakutou. Shoukabo, Tokyo, pp.169 (in Japanese).

VanderGheynst, J. S., Waker, L. P., and Parlange, J. Y., 1997: Energy transport in a high-solids aerobic degradation process: Mathematical modeling and analysis, Biotechnology Progress, 13, 238-248. 